International Research Journal of Engineering, IT \& Scientific Research
Available online at https://sloap.org/journals/index.php/irjeis/
Vol. 7 No. 4, July 2021, pages: 136-147
ISSN: 2454-2261
https://doi.org/10.21744/irjeis.v7n4.1719

\title{
Institutional Learning and Early Economic Impact Results Obtained by the Network of Business Development Centers in Chile
}

Rodrigo Ignacio Barra Novoa ${ }^{\text {a }}$

Article history:

Submitted: 9 March 2021

Revised: 18 April 2021

Accepted: 16 May 2021

\section{Keywords:}

business assistance CDN;

economic growth;

micro and small businesses;

public policies;

\begin{abstract}
Like other Latin American countries, Chile depends heavily on the activity of small and medium-sized companies to sustain some macro and microeconomic indicators. In particular, one of the productive development agencies that has taken a leading role in this objective is the Technical Cooperation Service (SERCOTEC). This institution has defined a set of support programs in different areas in order to meet the needs of this business segment. In this context, the article provides an overview of institutional learning, lessons learned, and economic impacts obtained by the Business Development Centers program, describing the central role of this innovative public policy that has responded actively and efficiently to the growth of the ventures and companies assisted between the years 2015-2019.
\end{abstract}

International research journal of engineering, IT \& scientific research (C) 2021. This is an open access article under the CC BY-NC-ND license (https://creativecommons.org/licenses/by-nc-nd/4.0/).

\section{Corresponding author:}

Novoa, R.I.B.

Researcher and Ph.D. student in Law and Economics Sciences at UCJC - Spain. Award Level 8 in Strategic Direction and Leadership by CMI, United Kingdom.

Social Economist and DBA

International Trade Advisor - Sercotec Arica Business Center

University of Tarapacá

Arica - Chile

Email address: rodrigobarra7@yahoo.es

${ }^{\text {a }}$ University of Tarapaca, Chile 


\section{Introduction}

Having a specific agency to meet the needs of smaller companies responds to the need that governments have to establish a model that favors economic development and has a positive impact on the quality of life and well-being of their population.

Based on the study of different institutions, SERCOTEC considers that the people who manage MSMEs have little time to be up to date on tools that could improve their businesses. Achieving improvements in this segment of companies would mean raising the standard regarding the quality of employment, the degree of informality in management and productivity levels. Therefore, for this institution its focus is on increasing competitiveness and strengthening business capabilities. This institution has deployed a set of programs nationwide, ranging from financing new ventures, technical assistance, and promoting business associativity. Like other public institutions, the challenge of SERCOTEC is to adjust its offer of programs to regional particularities, in this case, MSMEs. The definition of a regionalized model to support entrepreneurship and MSMEs has been achieved in recent years through the incorporation of new actors who have extensive experience in business development (Atienza \& Aroca, 2012; Brülhart \& Sbergami, 2009).

Within the public policy for the MIPYMES sector is the establishment of a Business Development Center network (CDN) that corresponds to an adaptation of the experience developed in the United States with the Small Business Development Centers (SBDC). This program, which has been in operation since the 1970s, promotes the growth, innovation, productivity and profits of small businesses through the improvement of business administration. One of the characteristics of the SBDC model is shared financing between the federal and state governments, which translates into the incorporation of interests from different territorial scales. The creation of an SBDC is linked to universities and community colleges, through which, a territorial deployment is achieved in various states and facilitates the offer of consulting services. The SBDC network consists of more than 1,100 institutions serving approx. 750 thousand clients annually (Ffrench-Davis, 2003; OECD, 2011).

The CDN Network has been implemented not only as a public initiative, but also involves different private actors, including universities, unions, chambers, foundations, among others. Therefore, the viability of the model lies in the public-private action with the interest of developing the business sector based on local characteristics. The network is made up of 51 Centers, of which 19 are linked to universities. The financing of the network is achieved through public funds and private contributions that may be non-pecuniary. The main service of the Centers corresponds to individual, detailed, confidential and high-value technical advice at no cost to the entrepreneur, businessperson or administrator. From a social perspective (Planas Serralta, 2016; Horton \& Mackay, 2003).

One of the notable aspects in the Chilean model is the evaluation of results and impacts of the CDN Network. The experience of the United States determined that one of the weaknesses of the model was the evaluation of the results of each center. In the Chilean case, the evaluation is achieved through two instruments: 1) a customer satisfaction survey and 2) an economic impact survey. Through them, it is possible to quantify the economic impact of the companies served in the CDN Network over time. For example, from the beginning of the program until December 2017, it is estimated that the companies that received advice created 3,180 new formal jobs.

\section{Literature Review}

\section{MIPYME and Sercotec sector}

Micro and small enterprises (MIPYMEs) constitute an important segment for national economic systems because they mean reducing unemployment levels and the low quality of existing jobs. In the case of Chile, the public sector has various agencies for the creation and development of companies. Among them, SERCOTEC is the entity whose target group is entrepreneurs, micro and small businesses (Paavola \& Adger, 2005; Caplow et al., 2011).

\section{Evolution and current situation of the MIPYME sector in Chile}

Achieving greater competitiveness in the segment has been the main need addressed by public institutions linked to micro and small companies. Studies on this segment of companies are scarce, but there are specific statistics for certain periods of time that allow us to measure their participation in the national economy.

Barra Novoa, R. (2021). Institutional learning and early economic impact results obtained by the network of business development centers in Chile. International Research Journal of Engineering, IT \& Scientific Research, 7(4), 136-147. https://doi.org/10.21744/irjeis.v7n4.1719 
Starting with micro-enterprises, in the period 2000-2006, the annual sales of this segment were close to 286 million UF on average with an average growth rate of $2.01 \%$. The number of companies remained close to 580 thousand units with a creation rate of $15.26 \%$ and a destruction rate of $12.46 \%$. In general, this segment does not present contractions in its total number as in total annual sales. The detail of these indicators can be seen in Table 1.

Table 1

Characteristics of Microenterprises in Chile between 2000 and 2006 ${ }^{\mathrm{b}}$

\begin{tabular}{llllllll}
\hline & 2000 & 2001 & 2002 & 2003 & 2004 & 2005 & 2006 \\
\hline Total Annual Sales (Million UF) & 250.5 & 252.1 & 262.7 & 268.0 & 272.6 & 278.1 & 282.6 \\
Annual Total Sales Growth Rate & 2.89 & 0.63 & 4.23 & 2.01 & 1.7 & 2.04 & 1.60 \\
$\begin{array}{l}\text { Number of Companies } \\
\text { (Thousands) }\end{array}$ & 555.8 & 565.5 & 580.6 & 587.3 & 587.4 & 580.0 & 586.5 \\
$\begin{array}{l}\text { Business Creation Rate } \\
\text { Business Destruction Rate }\end{array}$ & 14.43 & 16.25 & 15.28 & 15.25 & 15.16 & 15.16 & 15.40 \\
\hline
\end{tabular}

Source: Benavente and Külzer, 2008.

On the other hand, in the same period, small companies achieved sales of 763.7 million UF on average with a growth of 3.3\%. This segment was made up of 106.4 economic units with a growth rate of $4.35 \%$ and a destruction rate of $2.06 \%$. Like the micro-business segment, both the number of companies and total annual sales have maintained positive growth rates. The detail of these indicators is found in Table 2 .

Table 2

Characteristics of Small Companies in Chile between 2000 and $2006^{\mathrm{c}}$

\begin{tabular}{llllllll}
\hline & 2000 & 2001 & 2002 & 2003 & 2004 & 2005 & 2006 \\
\hline Total Annual Sales (Million UF) & 699.0 & 715.7 & 739.4 & 763.7 & 793.0 & 837.0 & 874.7 \\
$\begin{array}{l}\text { Annual Total Sales Growth Rate } \\
\begin{array}{l}\text { Number of Companies } \\
\text { (Thousands) }\end{array}\end{array}$ & 3.16 & 2.39 & 3.30 & 3.30 & 3.84 & 5.54 & 4.51 \\
$\begin{array}{l}\text { Business Creation Rate } \\
\text { Business Destruction Rate }\end{array}$ & 4.28 & 4.31 & 5.63 & 4.38 & 4.32 & 4.35 & 4.35 \\
\hline
\end{tabular}

Source: Benavente \& Külzer, 2008.

The micro-business segment is 5.5 times larger than small businesses, but annual sales are 2.8 times lower. This situation is not different from that observed in other countries. Considering this panorama, it is important to know in which areas micro and small companies are concentrated, in such a way, to contextualize business development. Benavente \& Külzer (2008) highlight that the creation rate, comparatively, is higher in the strata of smaller companies.

A study carried out by Pérez \& Suazo (2014) indicates that, in 2012, commerce and services are the areas where the largest number of microenterprises and SMEs are concentrated, both taking into account the criteria of annual sales and the number of workers. ${ }^{\mathrm{d}}$. It is worth mentioning that each criterion affects the total number of companies by segment. The detail regarding the distribution by item is found in Table 3 .

\footnotetext{
${ }^{\mathrm{b}}$ Between 1 and 2,400 Development Units.

${ }^{c}$ Between 2,401 and 25,000 Development Units.

${ }^{\mathrm{d}}$ In this case, microenterprises are considered to be those that have total annual sales between 1 and 2,400 Development Units and have between 1 to 9 workers. While SMEs were those that had total annual sales between 2,401 and 100,000 Development Units or between 10 and 249 workers.
} 
Table 2

Distribution of micro and small companies by total annual sales and number of workers

\begin{tabular}{lllll}
\hline & Micro-Businesses & \multicolumn{2}{l}{ Small and medium businesses } \\
\hline & $\begin{array}{l}\text { By Annual } \\
\text { Sales }\end{array}$ & $\begin{array}{l}\text { By Number of } \\
\text { Workers }\end{array}$ & $\begin{array}{l}\text { By Annual } \\
\text { Sales }\end{array}$ & $\begin{array}{l}\text { By Number of } \\
\text { Workers }\end{array}$ \\
\hline Agro-Fishing & 17,828 & 22,641 & 7,663 & 3,165 \\
Mining Industry EGA & 37,167 & 49,844 & 18,605 & 7,631 \\
Building & 26,174 & 36,526 & 15,406 & 5,894 \\
Commerce & 193,414 & 238,923 & 53,517 & 11,237 \\
Services & 137,020 & 178,276 & 51,088 & 12,033 \\
\hline
\end{tabular}

Sources: Suazo \& Pérez, 2014

The study also indicates that there are no significant differences in the rates of creation and destruction of companies by category in the period 2008 to 2012 . On the other hand, the fifth version of the Longitudinal Survey of Companies (ELE), developed by the National Institute of Statistics and the Ministry of Economy, Development and Tourism since 2007 (2019), indicates that 96.9\% of companies in Chile are MIPYMES and its sales represent a quarter of the total. In this context, an important aspect is the form of financing of micro and small enterprises in 2017. According to the data obtained in the ELE-5, the sources of financing of micro enterprises are concentrated in the use of their own resources, but unlike small companies, resources are also obtained from informal sources, commercial houses and state financing. In the case of small companies, new preferred financing alternatives are emerging that correspond to banks and suppliers.

Table 3

Distribution of companies according to financing sources

\begin{tabular}{lll}
\hline & Micro-enterprise & Small company \\
\hline Own resources or capital increase & $46.3 \%$ & $45.2 \%$ \\
Banks & $32.9 \%$ & $45.6 \%$ \\
Providers & $27.5 \%$ & $37.3 \%$ \\
Financial institutions other than banks & $2.3 \%$ & $5.0 \%$ \\
Related companies & $1.6 \%$ & $4.0 \%$ \\
Informal sources & $4.1 \%$ & $3.6 \%$ \\
Commercial houses & $3.9 \%$ & $2.7 \%$ \\
State funding & $1.5 \%$ & $1.0 \%$ \\
Other & $0.4 \%$ & $0.3 \%$ \\
He did not use any source of financing & $21.3 \%$ & $13.4 \%$ \\
\hline
\end{tabular}

Sources: Ministry of Economy, Development and Tourism, 2019

Regarding the relationship with customers, there is a difference between the two segments. In the case of microbusinesses, unlike small businesses, word of mouth agreements with clients are more common. However, noncompliance with dates or changes in the agreed conditions are less typical. Regarding the location of the clients, the number of clients in the same region where the micro-enterprise is located is greater than the small enterprises. However, both segments have a minimal participation of clients that are located abroad.

Table 4

Market and clients of micro and small companies

\begin{tabular}{lll}
\hline & Micro-enterprise & Small company \\
\hline Difficulties with clients & & \\
Delay in the agreed dates & $56 \%$ & $62 \%$ \\
Only verbal agreements & $47 \%$ & $42 \%$ \\
Changes in the agreed conditions & $24 \%$ & $31 \%$ \\
Location of the main clients & & \\
\hline
\end{tabular}

Barra Novoa, R. (2021). Institutional learning and early economic impact results obtained by the network of business development centers in Chile. International Research Journal of Engineering, IT \& Scientific Research, 7(4), 136-147. https://doi.org/10.21744/irjeis.v7n4.1719 


\begin{tabular}{lll}
\hline In the same region & $97 \%$ & $95 \%$ \\
In other regions of the country & $16 \%$ & $2.3 \%$ \\
Abroad & $3 \%$ & $3 \%$ \\
\hline
\end{tabular}

Sources: Ministry of Economy, Development and Tourism, 2019

From the information presented, it is possible to identify that both micro and small companies face a series of limitations for their development. In this sense, it is important to recognize which have been the main policies and programs developed for these business segments.

\section{Main limitations and challenges of smaller companies}

The International Labor Office together with the Technical Cooperation Service, in 2010, prepared a document describing a set of limitations and challenges faced by micro and small enterprises. Among them we can highlight the following:

- MSMEs face limited demand and intense competition that derives from the characteristics of the national market where per capita income is low, informality is significant, and business articulation is almost nonexistent;

- There is unfair competition for formalized MSMEs based on informal practices, which means noncompliance with legal, regulatory, labor and tax obligations;

- There are negotiation asymmetries between small companies and larger ones. There is an abuse in relation to payment times, the imposition of purchase prices, the establishment of clauses with costs for small businesses;

- There is a low proportion of small companies that innovate in the area of products, services and marketing and that use available public funds;

- There are structural limitations that prevent the incorporation of small companies in the international market. For example, the weakness of the financial structure to trade in dollars considering the volatility of the exchange rate;

- Low productivity due to lack of solid knowledge in business administration combined with the use of outdated technology. This aspect is influenced by the difficulty of obtaining adequate financing and the lack of information on available technologies;

- There is a lack of processes and strategies for permanent training of the workforce focused on the development of competencies. On the part of company administrators, there is a perception that workers do not need and / or have no interest in participating in training. From the offer, it is also believed that there are no courses adequate to the needs;

- Reduced capacity for growth due to the limited size of the domestic market and limited access to financing, particularly in the period of creation of the company until its first years of operation;

- Regarding financing, it is the conditions offered by the market that limit access, for example, the interest rate, credit history, guarantees, payment period, among others. In this sense, there is no financing in the market to start or innovate;

- The high degrees of informality produce unfair competition between companies and the lack of social protection for the people who work in them. There are more incentives to keep informal companies, for example, due to the cost involved in carrying out all the procedures required by the regulations.

Along with the above, in the particular case of entrepreneurship, Kantis \& Díaz (2008) identify the following challenges:

- The ventures are led by more than one person and in most cases, it meant complete dedication from the beginning;

- Access to state subsidies is an important condition at the beginning of ventures, understanding that the possibilities of obtaining bank financing are almost nil;

- The social circle of entrepreneurs is important because it is a way to obtain financing through angel investors.

- Entrepreneurs at the beginning of their businesses were able to establish alliances with their clients and suppliers, particularly using work experience; 
- Before founding a successful company, entrepreneurs had one or more previous companies as experience;

- For entrepreneurs, the learning process that allows the adaptation of the business model of companies throughout their existence is important. Few entrepreneurs had done a business plan or a serious business assessment before leaving.

As mentioned above, SERCOTEC plays a role in solving the gaps, needs and challenges of smaller companies. As an institution, it has created a dynamic public offering that has sought to create development opportunities for entrepreneurs. In this sense, it is important to recognize what its evolution has been.

\section{Institutional development of SERCOTEC and its programs since 1990}

Since the return to democracy, SERCOTEC has focused on supporting the small business segment. This agency remains subordinate to the Ministry of Economy, Development and Tourism. The main objectives of SERCOTEC have been:

- Improve the environment in which small and medium-sized companies develop;

- Promote union association of entrepreneurs;

- Promote greater municipal powers in matters of productive development;

- Encourage the use of information and communication technologies;

- Improve linkages between companies of different sizes;

- Develop new markets.

SERCOTEC's objectives are developed through programs associated with funds, most of which are assigned through contests. All EMTs that meet the requirements can apply individually or in association in accordance with the provisions established in each fund. The clients of this institution can be classified as follows:

- Entrepreneurs, formal and informal, and small businessmen who are in the initial stage and growth of their companies;

- Micro and small companies linked to market opportunities that are in the growth and consolidation stages.

Along with the previous segments, SERCOTEC has developed programs for formal micro and small businesses that have been victims of an emergency situation and has also created national competitions for specific business segments (e.g., National Craft and Design Contest). It is necessary to mention that through the customer orientation service, SERCOTEC provides information to citizens interested in starting or developing their businesses. Among the most important initiatives developed by SERCOTEC in recent years are:

- In 2005, the Seed Capital program began, which provides non-reimbursable resources to entrepreneurs. The selection of beneficiaries is defined by an open contest where people present their business ideas in different instances. This program continues to this day and also has, in some cases, the support of municipalities to support the application to the contest;

- In 2009, an Access to Finance Program for EMTs was created to stimulate formal financial institutions. Said instrument partially finances the operating expenses associated with the study and granting of credits. In this sense, financial institutions should apply guidelines, criteria and special policies, without affecting the ability to self-determine interests, terms, amounts and other conditions;

- In 2012, the Bee Capital was created to bridge gender gaps and promote female entrepreneurship. Like the seed capital fund, it finances business management actions (training, marketing, technical assistance and management advice) and investments in assets (assets, vehicles, formalization expenses and working capital);

- In 2014, the Network of Business Development Centers was created as a national program but executed regionally. This network seeks to solve problems related to limited management capacity and difficulties in accessing support services. This initiative was committed to the Productivity, Innovation and Growth Agenda 2014-2018. Axis 3 of this agenda defines that the Network would be based on the Small Business Development Centers (SBDC) for which a transfer of capacities and good practices from the United States

Barra Novoa, R. (2021). Institutional learning and early economic impact results obtained by the network of business development centers in Chile. International Research Journal of Engineering, IT \& Scientific Research, 7(4), 136-147. https://doi.org/10.21744/irjeis.v7n4.1719 
government was carried out. In general terms, the CDNs are coordinated through SERCOTEC, and their operation is tendered to private organizations.

\section{Modeling of the Network of Business Development Centers}

Arranged by the Productivity, Innovation and Growth Agenda, the government decides to implement a model of centers considering the experience of the United States. In this country, the network began in the late 70's, distinguishing itself by shared and equitable financing between federal and state governments and by providing business technical assistance services to small businesses.

\section{Origin, transfer and adaptation of the SBDC model in Chile}

SBDC was a pilot initiative implemented in the United States in the late 1970s. With more than 35 years of operation to date, there are more than 1000 centers in different states serving more than one million small businesses annually. Its services are based on free business consulting and low-cost training to improve business results. The model understands business development milestones as defining a new business, developing a business plan, obtaining new financing and developing an export offer.

In 2014, the transfer of knowledge was agreed in the Free Trade Commission of the Chile-United States FTA. Based on this agreement, a Memorandum of Understanding was signed for the promotion of entrepreneurship and growth of SMEs that begins to be implemented through a mission led by the Ministry of Economy, Development and Tourism. The adaptation of the model considered consultation with SME authorities and a national interest group; the development of an SBDC diploma for future operators; the development of a pilot plan; among other. 21 centers were opened in 2015, which increased to 51 in 2017, after calls for public tender. Along with this, a joint work is carried out with the University of Texas San Antonio for the transfer of good practices and operation with economic impact. The operators of the Centers in Chile were universities, productive development corporations and business associations. One of the aspects that the model deepens is the evaluation of the results and impacts on the clients served. The adaptation of the model has as an implicit objective the territorial deployment of a public offering executed by legal entities of public or private law. In this sense, each center defines its own conceptual and operational design framed in the regulations and manuals defined by SERCOTEC. The adaptation of the model has as an implicit objective the territorial deployment of a public offering executed by legal entities of public or private law. In this sense, each center defines its own conceptual and operational design framed in the regulations and manuals defined by SERCOTEC. The adaptation of the model has as an implicit objective the territorial deployment of a public offering executed by legal entities of public or private law. In this sense, each center defines its own conceptual and operational design framed in the regulations and manuals defined by SERCOTEC.

In addition to SERCOTEC and the CDN operator, the Regional Governments are involved, who propose the guidelines for the promotion of production in the local economic sectors; and private actors with whom strategic alliances are made to improve the services offered. The CDNs are focused on Smaller Companies (EMT), being those that obtain income of up to UF 25,000 per yeare. The Centers were conceptualized as:

"A space where the EMT and entrepreneurial business community will find comprehensive and effective support to develop their capabilities and their businesses, through high-value technical advice, general and / or specialized, together with a process of accompaniment and monitoring of their plans. of work, hoping to have an impact on their business, based on effort, perseverance and mutual commitment. "

The CDN Network is established throughout the country offering free assistance services for entrepreneurs, micro and small businesses. Said services consist of specialized technical assistance, accompaniment and follow-up whose objectives, on the one hand, are to strengthen production processes with the orientation of efficiency and market satisfaction and, on the other, to improve the managerial skills and management capacities of entrepreneurs. In this scheme, the accompaniment corresponds to comprehensive assistance and personalized coaching that includes field visits to production or service units. Finally, the follow-up is carried out on the companies attended that graduated

e As of November 30, 2020, 25,000 Development Units corresponds to 689,812,433 Chilean pesos or 905,897.09 US dollars. 
from the CDN, which allows measuring subsequent results and also identifying new needs that can be attended to. Along with the above, the CDN can complement the offer by providing specialized training which aims to promote a culture of sustained learning, contribute to raising the success rate, facilitate the acquisition of potential clients and prepare future entrepreneurs.

\section{Implementation of the Network of Business Development Centers}

The implementation of the CDN Network began in the second semester of 2015 with 33 operators of which 24 came from the Chile Emprende program developed by CORFO. Then 11 and 6 were created in 2016 and 2017 , respectively. In 2018 a new center was created with the National Fund for Regional Development. At the end of the 2014-2019 period, the national Network ends with 51 Centers. An important piece of information in the implementation is the number of strategic partners in each territory, which in 2018 totaled 580, among them 345 correspond to private entities such as universities, trade associations, chambers, corporations and foundations.

The objective of the Business Centers is "to contribute to the development of entrepreneurial and business capacities of the country's entrepreneurs through a comprehensive and effective offer of services in order to achieve economic impact in these" and as a mission "to promote growth, productivity, new networks and business opportunities, training and training of entrepreneurs contributing to the viability and sustainability of their businesses and workers". To align the different initiatives within these institutional guidelines, SERCOTEC established a Management and Operation Manual for the Business Centers.

The services offered by a CDN correspond to advice, training, access to financial offers, market research, link with the local productive system and the generation of alliances with institutions. For CDNs, clients are existing individuals or companies that adhere to the vision of the Center and formally request advice through which they receive technical advice to start a business and / or improve an existing one. Clients are categorized as follows:

- N1: entrepreneurial client, defined as a natural person with a business idea and intention to undertake, without starting activities in the Internal Revenue Service;

- N2: established companies, who need fast and professional advisory services;

- N3: Established companies with high growth potential in the short term, who need assistance in learning to manage a business that is growing fast and becoming a medium-sized company.

Clients are diagnosed by the CDN, through which a set of needs are identified that complete the work baseline. With this diagnosis, a work plan is defined, which functions as a management instrument between the CDN and the client. A set of activities are then agreed upon on a schedule defining responsible parties and deadlines.

\section{Characterization of the business park assisted by the program}

The companies considered potential clients by the CDN Network correspond to Micro-companies (Micro 3) and small companies (small 1, small 2 and small 3). According to the internal tax data, these segments can be dimensioned in the following Table 6.

Table 5

Number of companies classified according to their declared sales 2010-2017

\begin{tabular}{llll}
\hline Year & Micro3 & Small1-3 & Total \\
\hline 2014 & 226,977 & 186,190 & 413,167 \\
2015 & 234,864 & 191,507 & 426,371 \\
2016 & 240,314 & 197,101 & 437,415 \\
2017 & 246,071 & 194,321 & 440,392 \\
\hline
\end{tabular}

Source: Budget Office, 2019.

In 2017 , it is recognized that $52 \%$ of micro-entrepreneurs have not started activities in the Internal Revenue Service, $38.2 \%$ did so as a natural person and only $9.5 \%$ as a legal person. Only $20 \%$ of entrepreneurs have participated in training in recent years and $20 \%$ solve their financing needs with informal lenders.

Barra Novoa, R. (2021). Institutional learning and early economic impact results obtained by the network of business development centers in Chile. International Research Journal of Engineering, IT \& Scientific Research, 7(4), 136-147. https://doi.org/10.21744/irjeis.v7n4.1719 
In this context, the evaluation of the CDNs developed by the Budget Office (2019) establishes that $11 \%$ were small companies, 64\% were micro-companies, $18 \%$ were entrepreneurs and less than $1 \%$ were medium and large companies. However, there is no information at the regional level that would allow us to identify a more detailed context regarding the companies served.

\section{Results and Discussions}

\section{Results and Impacts of the business development model in the MSME sector}

The efficiency of public spending is focused on changes in economic and social conditions and is the way in which the results and impacts of the CDN Network are evaluated. Recently, the Budget Office, in the evaluation of 687 state programs, established that $25 \%$ of them had an inadequate targeting. This section describes the form of evaluation of the CDN Network, understanding the economic impact up to the sustainability of the policy.

\section{Economic impact measurement model}

The Centers have an impact on the formation of new companies, the creation of jobs, the formalization and tax participation, the growth of local economies, among others. The evaluation carried out by Valenzuela et al. (2018) indicates "an increase in the number of total workers, number of formally hired workers and number of workers with full-time jobs" (p.15). To achieve impact measurement, all the companies served are diagnostic to identify a set of gaps that the work plan should resolve.

The impacts are measured through the Neoserra system, although other types of information are captured using forms provided by the Centers. Neoserra is a customer relationship management (CRM) system developed by OutreachSystems that, among other functionalities, allows the preparation of reports based on economic indicators. The general administration of the system is developed by SERCOTEC, which also defines the performance, impact and management indicators based on the annual negotiation minutes with the Centers. Some of the impact indicators that are recorded in the Neoserra system are:

- Number of companies with increased sales;

- Number of companies advised with new formal jobs;

- Number of formalized companies;

- Number of new exporting companies;

- Number of companies advised with new contracts with clients;

- Number of companies advised with new products and / or services.

Part of the information is obtained when clients complete form T3 "Economic Impact Survey". The application of the survey occurs differently according to the category of the customer. Clients N1 and N2 are surveyed at the end of the work plan or at an important milestone. In the case of N3 clients, they are asked to complete them annually. The survey is verified by the counselor and the director of the Center in order to correlate the information with the counseling and / or training sessions. The information from each survey used in an aggregate way in order to demonstrate the work carried out by the Centers at the individual and group level.

\section{Early results of the first impact evaluation of the program}

The program developed by SERCOTEC was able to fulfill the commitment established in the Productivity, Innovation and Growth Agenda within a period of three years. This meant the regionalization of a public policy that aims to support the EMT, specifically, the offer of services for the improvement of management capacities. The CDN Network has been evaluated by different instances, in particular, they have been focused on recognizing the economic impacts achieved from its implementation.

The Evaluation Department of the Budget Directorates evaluated the CDN program with a good performance. The report prepared by this institution indicates that the results of the Centers are as follows: 
- The percentage of beneficiaries who increased their sales and attributed it to the intervention of the program has grown from $12 \%$ in 2016 to $26 \%$ in 2018.

- In the period evaluated 2015-2018, the program reports a $6 \%$ increase in employment, $14 \%$ increase in investment, and $32 \%$ of beneficiaries with at least one improvement in the result variable (sales, employment, and investment) with respect to of the total clients advised.

- Using data from the Internal Revenue Service, it is observed that, of a total of 6,820 CDN beneficiaries in 2016, 54\% increased sales in 2017, compared to $42 \%$ for those companies that were not advised.

On the other hand, Valenzuela et al. (2018) affirm that "the advice provided by CDNs in Chile has a positive and economically important effect in terms of job creation and formalization" (p. 22). It is worth mentioning that, in Chile, $30 \%$ of the workforce is informal and $65 \%$ is concentrated in micro-enterprises. Reducing informal employment is one of the objectives promoted by the International Labor Organization, more currently, considering the volatility of growth in Latin American economies. Thus, many companies make adjustments in employment according to economic cycles, thus affecting the quality of life of the population. In this regard, the activities carried out by the Centers contribute to the reduction of poverty (Bansal \& Bogner, 2002; Orihuela, 2013).

\section{Institutional learning and lessons learned}

The CDN Network allows you to define a set of learnings between them:

- The territorial relevance of public policy;

- Integration in alliances of public and private actors;

- Measurement of the economic impact of the intervention of the Centers;

- The establishment of a computer support for the control and monitoring.

Although there is a data confidentiality policy, it is important to disaggregate the evaluation at the regional level. It is possible that the performance of some Centers is leveraging others. Likewise, there is no evaluation for companies that do not have positive results. The self-evaluation carried out by the Centers has an important bias because only companies with positive results are considered, for example, 76\% of N1 beneficiaries did not have increases in their sales in 2018, for which there is no explanation.

\section{Sustainability of the SBDC / CDN model in Chile}

The sustainability of the model not only depends on the existence of a multi-year budget, but also on the improvement of information regarding the results and impacts of the CDN Network. It is therefore necessary to establish new indicators that make it possible to identify results that the beneficiaries have achieved with the action of the CDNs, for example, the obtaining of profits, the formality of the management with third parties, the improvement of products or services, the degree of sustainability achieved, among others. So far, the methodology available to evaluate is based on the experience of the United States. The evaluation of the CDN Network carried out by the Budget Directorate suggests developing a comparative performance process.

Along with the above, the Budget Office considers it necessary to improve the program's strategy considering the following areas of action:

- To whom to deliver services, for how long and / or in how many opportunities;

- Comparison of expected results vis a vis obtained results;

- Measurement of the cost of the intervention;

- Evaluation of results at the level of a target population;

- Comparison of the intervention between the CDNs and with other similar programs.

Barra Novoa, R. (2021). Institutional learning and early economic impact results obtained by the network of business development centers in Chile. International Research Journal of Engineering, IT \& Scientific Research, 7(4), 136-147. https://doi.org/10.21744/irjeis.v7n4.1719 


\section{Conclusion}

Designing and implementing policies and programs has been a fundamental role that governments play in boosting economies. In a range of alternatives, the institutions initially aimed at the productive development of the companies without distinguishing their size. As the studies on the different business segments deepened, the smaller ones emerged as a segment that particularly influences employment. From this focus, the policies focused on developing entrepreneurship and innovation capacities. These policies are compared between countries by international organizations, for example, Babson College produces a periodic report that compares the entrepreneurial capacities between different countries.

After the return to democracy, the institutionality is linked to the programmatic agendas defined in each of the governments. More formally, a set of diagnoses, formulated by public institutions such as universities, begins to guide the definition of policies. In this regard, SERCOTEC is the government agency with direct concern for startups and smaller companies. For her, the definition of instruments is a complex task due to the number of companies that is over 500 thousand. In particular, budgetary limitations and the need to have coverage in all regions in order to increase the efficiency of public spending emerge as conditioning factors.

Given the above, the Network of Business Development Centers is developed as an instrument whose potentialities are particularly defined by the involvement of other public and private actors. Taking the experience of the United States as a reference, this network has a territorial coverage that other public initiatives do not have and has also configured a service offer consistent with the local reality. The methodology used has incorporated customer relationship management tools that have made it possible to achieve remarkable performance, deriving the typical difficulties in controlling and monitoring the implementation of a public policy.

Among the tools to achieve good management, SERCOTEC has had an operations manual, a monitoring computer system, annual performance agreements, among others. One strength of the Network is the ability of the Centers to establish an offer consistent with the needs of the regional authorities and the target population. Each region has a different reality. In order to evaluate the performance of the entire Network, you consider measuring customer satisfaction at the time of finalizing the work plan and also knowing the economic impact from the intervention carried out by each Center. The qualitative and quantitative information has been consolidated and is presented as the performance of public policy. In this regard, there is still room to improve the indicators, for example,

Currently, due to the COVID-19 pandemic, entrepreneurs, micro and small businesses have required not only financial support, but also new capacities to face the new market conditions. In 2019, the way of marketing changed substantially with the incorporation of technologies that, although they existed, were not widely used. In this space, the CDN Network helped the owners or managers of smaller companies have the alternative of improving their capacities, thus increasing the chances of survival. This is an advantage of the alliance between SERCOTEC and the operators, since there is a capacity to adjust the offer to local needs, without requiring the development of a specific instrument or change of any regulation.

\section{Conflict of interest statement}

The author declared that he has no competing interest.

Statement of authorship

The author has a responsibility for the conception and design of the study. The author has approved the final article.

Acknowledgments

I am grateful to two anonymous reviewers for their valuable comments on the earlier version of this paper. 


\section{References}

Atienza, M., \& Aroca, P. (2012). Concentration and growth in Chile: an ignored negative relationship. EURE (Santiago), 38 (114), 257-277.

Bansal, P., \& Bogner, W. C. (2002). Deciding on ISO 14001: economics, institutions, and context. Long Range Planning, 35(3), 269-290. https://doi.org/10.1016/S0024-6301(02)00046-8

Benavente, JM, \& Külzer, C. (2008). Creation and destruction of companies in Chile. Economic Studies , 35 (2), 215-239.

Brülhart, M., \& Sbergami, F. (2009). Agglomeration and growth: Cross-country evidence. Journal of Urban Economics, 65(1), 48-63. https://doi.org/10.1016/j.jue.2008.08.003

Budget Office (2019). Final evaluation report of the business development program in the territories (Business development centers).

Caplow, S., Jagger, P., Lawlor, K., \& Sills, E. (2011). Evaluating land use and livelihood impacts of early forest carbon projects: Lessons for learning about REDD+. Environmental Science \& Policy, 14(2), 152-167. https://doi.org/10.1016/j.envsci.2010.10.003

Ffrench-Davis, R. (2003). Chile, between neoliberalism and growth with equity. New Society, 183, 70-90.

Horton, D., \& Mackay, R. (2003). Using evaluation to enhance institutional learning and change: recent experiences with agricultural research and development. Agricultural Systems, 78(2), 127-142. https://doi.org/10.1016/S0308521X(03)00123-9

International Labor Office and Technical Cooperation Service (2010). The situation of micro and small companies in Chile. https://www.ilo.org/empent/Publications/WCMS_143060/lang--es/index.htm

Kantis, H. and Díaz, S. (2008). Innovation and Entrepreneurship in Chile: An X-ray of Dynamic Entrepreneurs and Their Business Practices. Endeavor Chile.

Ministry of Economy, Development and Tourism (2019). ELE-5 Bulletin: Main Results. Commercial and Industrial Policy Division.

OECD (2011), OECD Regional Outlook 2011: Building Resilient Regions for Stronger Economies, OECD Publishing, Paris, https://doi.org/10.1787/9789264120983-en.

Orihuela, J. C. (2013). How do "mineral-states" learn? Path-dependence, networks, and policy change in the development of economic institutions. World Development, 43, 138-148. https://doi.org/10.1016/j.worlddev.2012.10.004

Paavola, J., \& Adger, W. N. (2005). Institutional ecological economics. Ecological economics, 53(3), $353-368$. https://doi.org/10.1016/j.ecolecon.2004.09.017

Planas Serralta, L. (2016). Innovation systems and strategies in regions of Chile [Doctoral Thesis, University of Valladolid]. UVaDOC. http://uvadoc.uva.es/handle/10324/16795

Suazo, G. and Pérez, J. (2014). Business Demography in Chile (Statistical Economic Studies No. 108 September 2014). Central Bank of Chile.

Valenzuela, P., Ramos, J. and Andrade, M. (2018). Impact Evaluation Business Development Centers in Chile: Generating employment through smaller companies [Public Systems Series No. 15]. Center for Public Systems.

Barra Novoa, R. (2021). Institutional learning and early economic impact results obtained by the network of business development centers in Chile. International Research Journal of Engineering, IT \& Scientific Research, 7(4), 136-147. https://doi.org/10.21744/irjeis.v7n4.1719 